\title{
ESTUDIO DEL DESARROLLO RADICAL EN ALMÁCIGO DE HÍBRIDOS F1 DE CAFÉ OBTENIDOS POR CULTIVO DE TEJIDOS
}

\author{
Fabián Echeverría ${ }^{1 / *}$, Miguel Barquero*, David Rodríguez* \\ Palabras clave: Aclimatización, Híbrido F1, café, Jiffy®, invernadero, in vitro, RITA®. \\ Keywords: Aclimatization, Hybrid F1, coffee, Jiffy®, green house, in vitro, RITA®.
}

Recibido: 02/09/13

\section{RESUMEN}

Plántulas de Híbridos F1 de café, obtenidas por embriogénesis somática indirecta, fueron aclimatizadas bajo condiciones de invernadero, en 2 tipos de contenedores: bandeja con sustrato convencional y malla biodegradable con turba comprimida (Jiffy $\left.{ }^{\circledR}\right)$. A los 2 meses, las plántulas fueron transferidas a bolsa con sustrato convencional y desarrolladas en el vivero. Se evaluó el desarrollo y calidad de la planta 8 meses después de su crecimiento en almácigo. Se encontró $33 \%$ de raíces rectas y $65 \%$ con morfologías anormales como estrangulamientos, serpenteadas y bifurcaciones, las cuales tuvieron respectivamente menores valores en los parámetros de largo, grosor y peso, tanto en el sistema radical como aéreo. En cuanto al tipo de contenedor, se obtuvo mayor crecimiento en las plántulas desarrolladas en Jiffy ${ }^{\circledR}$ con respecto a las de bandejas, sin embargo, aquellas que preservaron la envoltura durante la etapa de vivero, tuvieron menor crecimiento y desarrollo, con respecto de aquellas que les fue retirado. Se recomienda retirar la cobertura del Jiffy ${ }^{\circledR}$ previo a la siembra en bolsa, así como mejorar la técnica de inmersión temporal para evitar anormalidades morfológicas en los embriones producidos.

\footnotetext{
1 Autor para correspondencia. Correo electrónico: fecheverria@icafe.cr
}

Aceptado: 02/12/13

\begin{abstract}
Root development in F1 coffe hybrids obtained by tissue culture. F1 Hybrid seedlings, obtained by indirect somatic embryogenesis, were acclimatizated under greenhouse conditions, separated in 2 types of container: biodegradable mesh with compressed turf $\left(\right.$ Jiffy $\left.{ }^{\circledR}\right)$ and the other on conventional tray with soil and rice husk. Two months later, the plantlets were transferred to bags with conventional substrate and grown under nursery conditions. Development and quality of the plants were evaluated after growing during 8 months under conventional management. It was found that $33 \%$ had straight roots, however $65 \%$ had abnormalities, such as constrictions and loops, twists, bifurcations, among others, corresponding to lesser values in length, thickness and weight, both in the radical system as well as aerial. In regard to container type, acclimatizated plants grown in Jiffy ${ }^{\circledR}$ showed better growth than those in trays; however, those on which the cover was kept during the nursery stage were less developed, as compared to those were the cover was removed. It is recommended to remove the Jiffy ${ }^{\circledR}$ cover before planting in the soil bag in the nursery, and improve the temporary immersion technique to prevent morphological abnormalities of the embryos produced.
\end{abstract}

\footnotetext{
* Centro de Investigaciones en Café. Instituto del Café de Costa Rica. Costa Rica.
} 


\section{INTRODUCCIÓN}

La reproducción asexual del café por medio de cultivo de tejidos, ha sido una técnica de importancia para el mejoramiento genético, debido a las múltiples herramientas disponibles para el desarrollo de nuevos métodos de selección, reproducción y propagación (De Los Santos et ál. 2006, Etienne et ál. 2002). Para el cultivo de café, los principales estudios se han basado en la obtención de callos o aglomerados de células desdiferenciadas, con capacidad de regenerar otros tejidos, órganos y sistemas (Gatica et ál. 2007). Desde 1970, estudios realizados con plantas de C. canephora por Starisky; y posteriormente por Sondahl y Sharp en 1977 para C. arabica, señalaron que es posible inducir la embriogénesis a partir de tejidos asexuales y regenerar plantas completas. Dicho concepto fue también utilizado por Yasuda (1985), quien logró regenerar sin un callo, embriones somáticos. Es por ello que el desarrollo de la técnica de cultivo de tejidos mediante embriogénesis somática (ES), representa una gran oportunidad de aprovechamiento para el desarrollo de nuevas investigaciones y materiales de café.

En los años 80's, se inició un programa de mejoramiento en la región centroamericana entre PROMECAFE-CIRAD-CATIE, con el cual se realizó una prospección de materiales silvestres de interés para cruzar con variedades comerciales y generar nuevos materiales híbridos, los cuales en su primera generación (F1), fueran micropropagados por medio de ES (Etienne et ál. 1998). Las evaluaciones en campo permitieron la selección de materiales que posteriormente fueron propagados por esta técnica. Resultado de ello fueron los Híbridos F1 denominados como "Centroamérica" y "Milenio".

La técnica de embriogénesis somática actualmente empleada (Boxtel y Berthouly 1995, Etienne et ál. 1999) incluye la introducción de un segmento de hoja en condiciones in vitro, asépticas y controladas, para la inducción de un callo de alta frecuencia o secundario, del cual se obtendrán masas celulares que serían multiplicadas en medios líquidos durante un tiempo determinado, hasta alcanzar una mayor cantidad de proembriones. Posteriormente, son colocadas en medios semisólidos donde adquieren la conformación de un embrión que germina en un sistema de inmersión temporal llamado RITA $®$, en el cual el material vegetal está sobre una rejilla y nutrida por diferentes inmersiones intermitentes que permiten un acelerado desarrollo del embrión y conversión a plántula. Durante este proceso, los embriones adquieren el desarrollo de hojas cotiledonares y sistema radical. Posterior al proceso de diferenciación a plántula, los embriones son preaclimatizados en el laboratorio, y luego aclimatan bajo condiciones de ambiente controlado. Una vez superada la aclimatización, la planta es sembrada en almácigo y desarrollada convencionalmente hasta su siembra en campo.

A pesar de la factibilidad de reproducción clonal y vegetativa de los materiales de café a través de ES, es necesario el perfeccionamiento de los procesos de selección y manejo para el adecuado desarrollo de las plántulas desde sus etapas de aclimatización, debido a que a nivel de campo se ha observado mortalidad que se presume está asociada a problemas del sistema radical.

Con el objetivo de esclarecer el efecto de la turba comprimida y la presencia de anormalidades en el sistema radical a nivel de almácigo, se estableció un experimento entre el 2011 y 2012, para material de café proveniente de ES multiplicado comercialmente.

\section{MATERIALES Y MÉTODOS}

La investigación se inició en el invernadero de Agribiotecnología de Costa Rica S.A., ubicado en el Coyol de Alajuela, durante la etapa de aclimatización, y en el Centro Cantonal de Grecia en Santa Gertrudis Norte, durante la etapa de almácigo. Las evaluaciones del almácigo fueron realizadas en el Centro de Investigaciones en Café (CICAFE), ubicado en San Pedro de Barva, Heredia.

Las plantas utilizadas fueron producidas mediante la técnica de embriogénesis somática del genotipo L13A44, con la metodología 
desarrollada por Berthouly y Michaux (1996) y algunas modificaciones realizadas por el Laboratorio de Cultivo de Tejidos de Agribiotecnología de Costa Rica S.A. La fase de aclimatización fue desarrollada bajo condiciones controladas de invernadero, con una humedad superior al 90\% realizada con nebulización y aspersión, y una temperatura superior a $\operatorname{los} 25^{\circ} \mathrm{C}$, durante 2 meses. Se inspeccionaron las plántulas provenientes de una etapa de preaclimatización en laboratorio y sembraron en 2 diferentes sustratos: 200 plántulas se sembraron en turba comprimida (Jiffy® de 30 x 70 mm), y 100 en bandejas con una mezcla de granza y suelo. Posterior a este periodo, se trasladaron las plántulas al almacigal del Centro Cantonal de Grecia, en Santa Gertrudis Norte, donde se sembraron en bolsas de $15 \mathrm{x}$ $20 \mathrm{~cm}$ con una mezcla de suelo, granza y broza en proporción 3:1:1: 100 plántulas de Jiffy® con su cubierta, 100 sin la cubierta y las otras 100 de bandejas en forma convencional. Las mismas fueron atendidas bajo el mismo manejo comercial de almácigo.
Posterior a los 8 meses de desarrollo, se trasladaron al Centro de Investigaciones en Café (CICAFE), en San Pedro de Barva, Heredia, donde se retiraron las plantas de las bolsas, y lavaron cuidadosamente las raíces, con el objetivo de determinar el tipo de morfología, la longitud y área de cobertura de raíces, así como el peso fresco de la planta total, el grosor, longitud y número de pares de ramas del sistema aéreo. La información obtenida fue analizada a partir de las varianzas asociadas a cada valor, para comprobar la existencia de diferencias estadísticas entre los tipos de contenedores empleados en vivero.

\section{RESULTADOS}

Durante las diferentes etapas de desarrollo de las plantas, desde la siembra del material a aclimatizar hasta la evaluación posterior del almacigal se observaron diversas malformaciones en el sistema radical, principalmente enrollamientos, dobleces, y engrosamientos (Figuras 1 y 2).

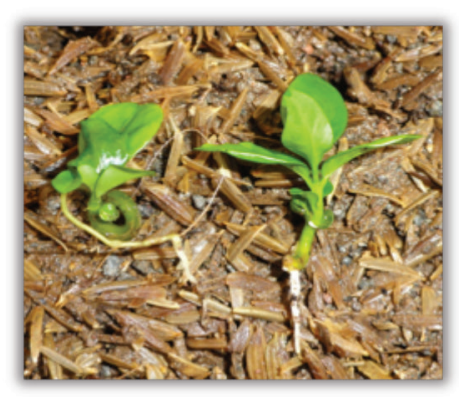

A

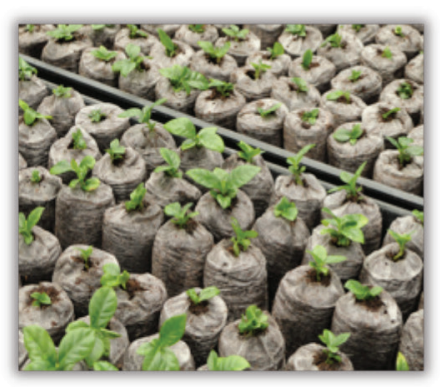

B

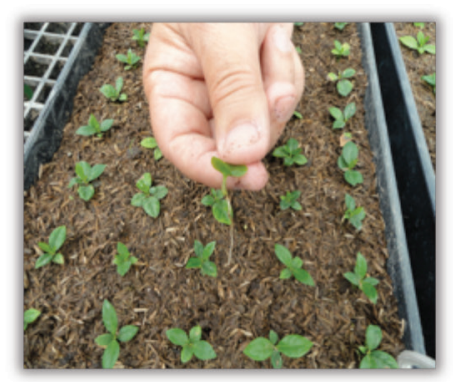

$\mathrm{C}$

Fig. 1. Plántulas en aclimatización. A: Plántula anormal (izquierda), Plántula deseable (derecha); B: Siembra en Jiffy ®i); Siembra en Bandeja. 


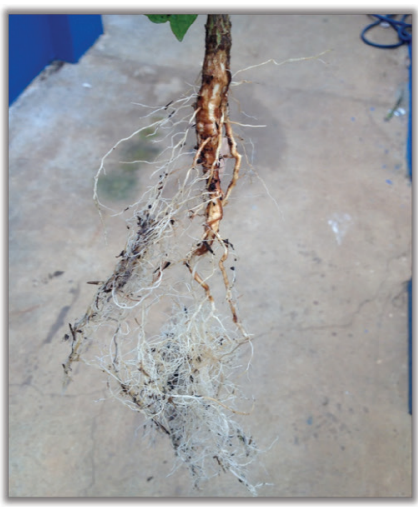

A

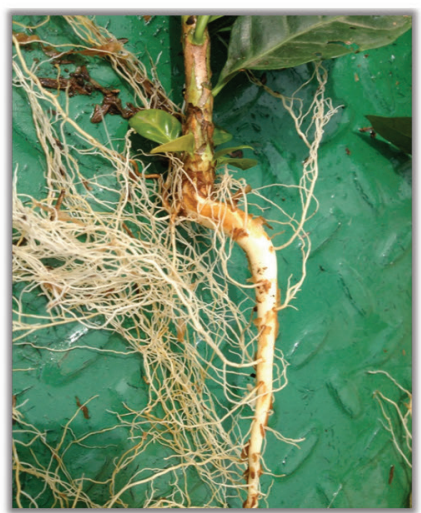

$\mathrm{D}$

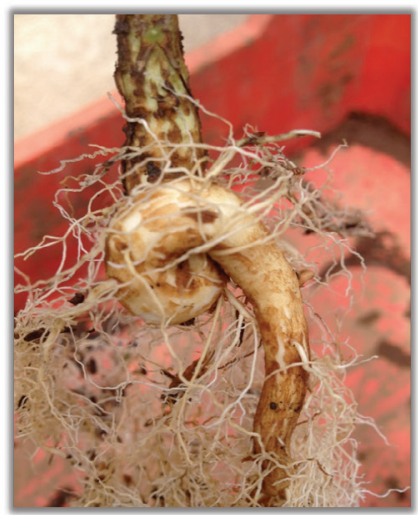

G

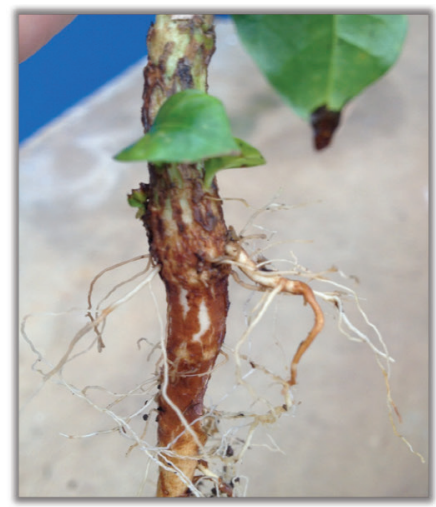

B

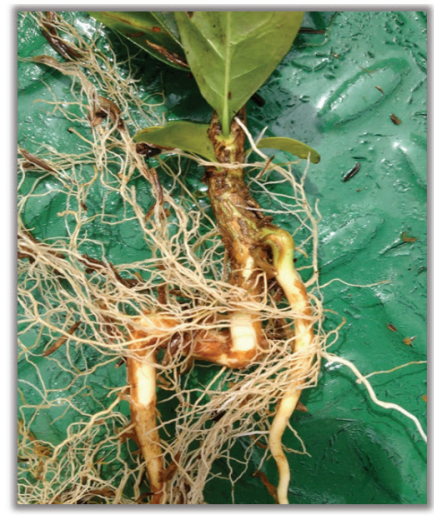

E

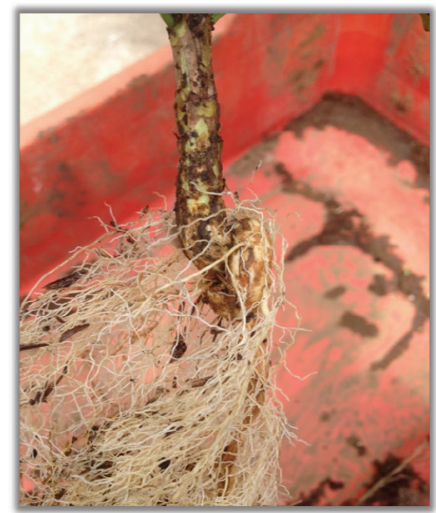

$\mathrm{H}$

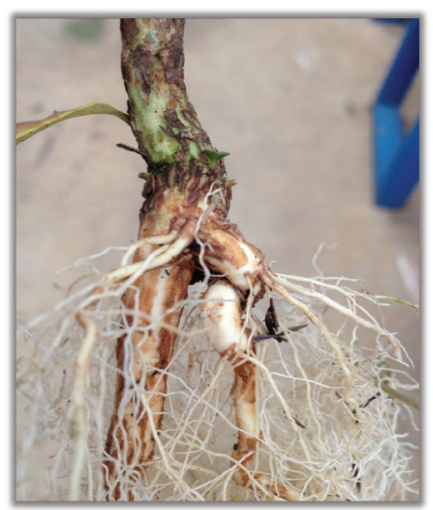

C

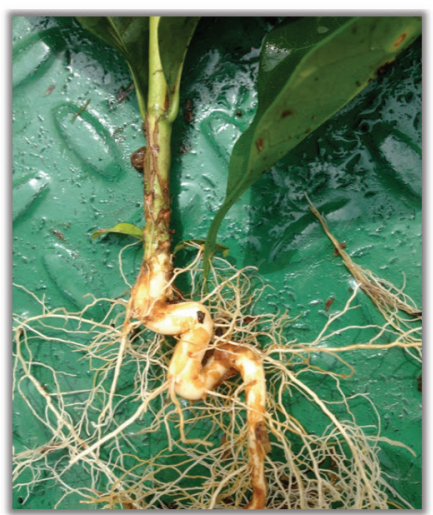

$\mathrm{F}$

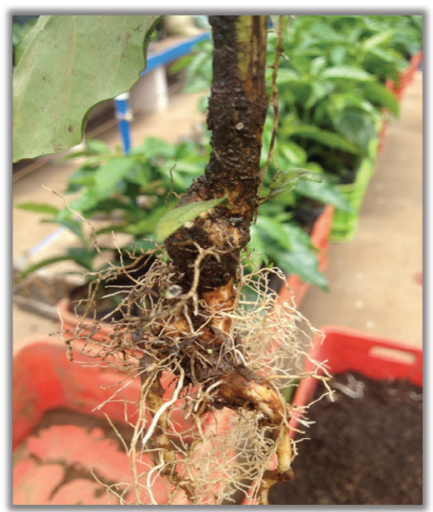

I

Fig. 2. Categorías de tipos de morfologías encontradas en el sistema radical, independientemente de los tratamientos. A: Raíz Pobre; B: Sin secundarias; C: Estrangulada; D: Recta; E: Bifurcada; F: Serpenteada; G: En "U”; H: Con nudo; I: Engrosada. 
Para el estudio, no se seleccionaron plántulas para favorecer la aleatoridad de la investigación. De acuerdo con lo observado en las evaluaciones de almácigo, independientemente del tratamiento, se determinó la presencia de raíces bifurcadas y serpenteadas

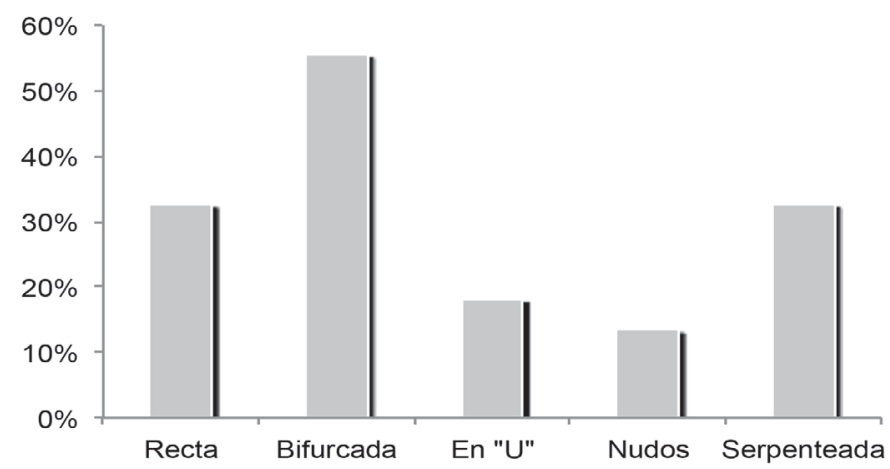

que representaron 56 y $33 \%$, respectivamente, seguido de malformaciones de la raíz en forma de "U" y con varios nudos que representaron 18 y $14 \%$, respectivamente y aproximadamente un $33 \%$ de raíces rectas (Figura 3).

Fig. 3. Frecuencia de aparición de morfologías en el sistema radical. Varias pueden aparecer en un mismo sistema radical.

Según los tratamientos, la longitud de las raíces no fue estadísticamente diferente, al presentar un promedio de $31 \mathrm{~cm}$ (Figura 4). Por otra parte, el área o diámetro que cubría la raíz si tuvo por su lado diferencias significativas, pues fue superior con el tratamiento Sin Jiffy ${ }^{\circledR}$ al presentar $8,7 \mathrm{~cm}$, en comparación con los otros 2 tratamientos de $6,4 \mathrm{~cm}$ en promedio. El peso total de las plantas Sin Jiffy®, fue mayor estadísticamente al de bandejas y con Jiffy®, mostró un promedio de 60, 37 y 26 gramos, respectivamente. A pesar de que los otros parámetros de desarrollo aéreo no fueron significativos, la altura para el tratamiento que se le retiró la cubierta, mostró un promedio de $6 \mathrm{~cm}$ más con respecto a los demás tratamientos.

En cuanto a las plantas con arquitectura recta, con torceduras o enrollamientos, el desarrollo para aquellas plantas con sistema radical recto (deseable), mostró que estadísticamente sólo los parámetros de peso y longitud del tallo fueron significativos con diferencias de aproximadamente $23 \mathrm{~g} \mathrm{y} 7 \mathrm{~cm}$, respectivamente (Figura 5).

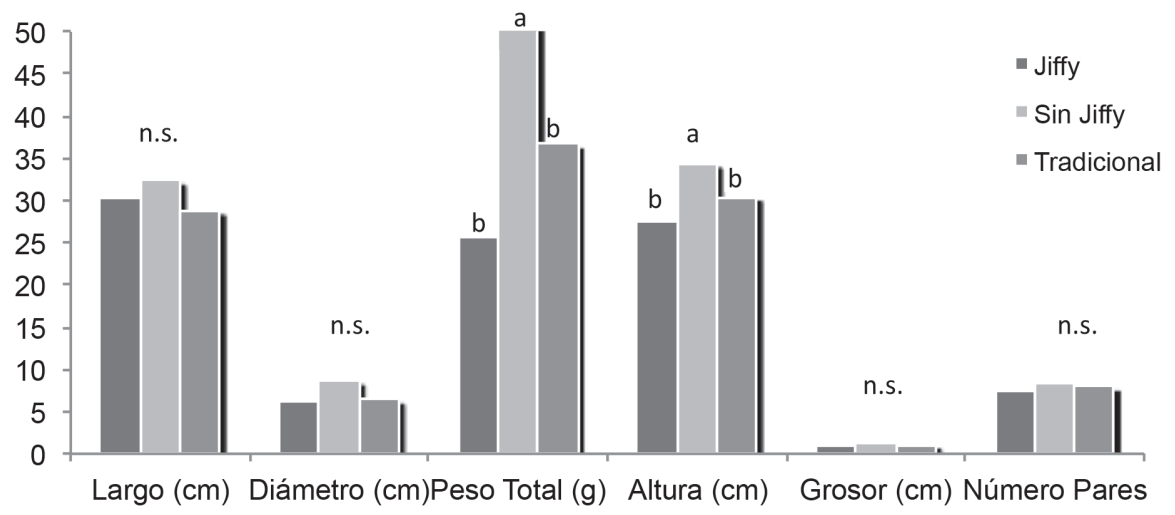

Fig. 4. Desarrollo del sistema radical y aéreo de plantas según medio de desarrollo. Largo y diámetro de raíces, y altura, grosor y pares de ramas en tallo.

Prueba LSD Fisher. Letras distintas indican diferencias significativas $(\mathrm{p}=0,05)$. 


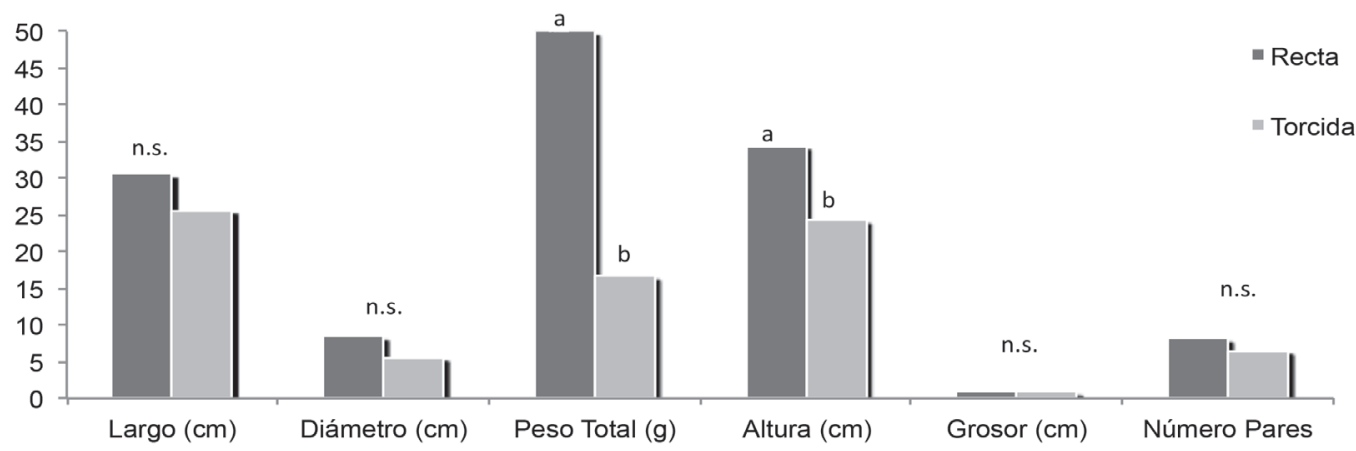

Fig. 5. Desarrollo del sistema radical y aéreo de plantas según estructura radical. Largo y diámetro de raíces, y altura, grosor y pares de ramas en tallo.

*Prueba LSD Fisher. Letras distintas indican diferencias significativas $(p=0,05)$.

\section{DISCUSIÓN}

La información registrada en el presente estudio, evidencia que para el caso de estos materiales de café reproducidos por cultivo de tejidos a través de la técnica de embriogénesis somática indirecta, la presencia de anormalidades especialmente del sistema radical, son evidentes después del proceso de germinación en sistemas de inmersión temporal tipo RITA $®$, los cuales junto a limitantes mecánicas como lo son las telas de algodón que recubren al Jiffyß, dificultan el desarrollo adecuado de la planta, al generar deformaciones en la raíz principal y secundarias.

Estudios realizados por Barry-Etienne et ál. (2002b), señalan que la producción de embriones en sistema de inmersión temporal tipo RITA $®$, genera alta heterogeneidad morfológica de cotiledones, tallos y raíces en las plántulas, con un consecuente detrimento de la conversión de embrión a plántula en la aclimatización, como retardamiento en el desarrollo a nivel de almácigo. Dichos resultados, son congruentes a lo evidenciado en el presente estudio, dónde la limitación en primera instancia de la calidad de la plántula empleada en los diferentes tratamientos, revela la existencia de anormalidades que afectaron el desarrollo, reflejadas a través de la disminución de un $70 \%$ en su peso y un $30 \%$ la altura del tallo, con respecto a aquellas que mantenían una buena rectitud radical (Figura 5). En cuanto a la anatomía del sistema radical, la información obtenida indica un porcentaje inferior al 33\% de raíces rectas, lo cual evidencia que la técnica en laboratorio debe optimizarse para evitar no sólo anormalidades, y además alcanzar mejor calidad para asegurar la supervivencia y rendimiento. Dichas evidencias apuntan a que una buena técnica de germinación en el sistema de inmersión temporal, podría corregir en gran medida, la calidad de plántula durante la aclimatización y posterior desarrollo en almácigo, con la mejora en el rendimiento por efecto de cantidad de embriones de óptima calidad, así como los costos operativos durante las etapas de endurecimiento y posterior desarrollo en vivero.

Por su parte, la turba comprimida evidenció ser adecuada durante la etapa de aclimatización, posiblemente debido al tipo de sustrato, que mantiene menos saturada la humedad de la raíz, al permitir mayor aireación. Dichas conclusiones fueron similares a las obtenidas por Costa et ál. (2008), quienes mencionaron que existe una mayor producción de hojas cuando se utiliza un sustrato de perlas de arroz carbonizado, comparado con sustrato convencional. Los autores señalan que la generación de espacios entre poros, permiten una mejor aireación y drenaje. 
Azofeifa et ál. (2009) por su parte, señalaron que en la aclimatización de caoba (Swietenia macrophylla), el Jiffy ${ }^{\circledR}$ permitió una sobrevivencia del $70 \%$, mientras una mezcla de suelo con Glomus fasciculatum fue nula. Lo determinado en ese estudio, refuerza el hecho que la turba comprimida colabora en la sobrevivencia del material durante la aclimatización y puede ser utilizada para la producción de plántulas, así como plantas forestales como Gmelina sp. (Rojas et ál. 2004). A pesar que en el presente ensayo la sobrevivencia no fue un parámetro evaluado, en ambos sustratos utilizados, no hubo diferencias apreciables.

En cuanto al desarrollo en almácigo, los resultados evidenciaron que una buena morfología de la plántula, favorece un adecuado desarrollo de las plantas, tanto en aumento del peso como la longitud del tallo, lo cual es congruente con lo obtenido por Barry-Etienne et ál. (2002b), quiénes evidenciaron que una adecuada selección de embriones, a partir de una clasificación a nivel de cotiledones, permite la adecuada conversión ex vitro del 63\%, con aumento entre un 16 y $33 \%$ en el rendimiento.

Alternativas para mejorar la eficiencia posteriormente ex vitro, parecen existir a partir de una buena selección de la plántula, y también del adecuado uso del sustrato. LeBude et ál. (2006), en ensayos de enraizamiento en pinos a partir de estacas y desarrollo de las mismas, reportan que conforme se incrementa el volumen de capacidad del contenedor tipo turba comprimida, mayor es el peso acumulado y desarrollo de la planta. Dichos resultados señalaron que además del factor genético asociado a cada tamaño de contenedor, el desarrollo es limitado en proporción lineal al volumen que puede contener el recipiente para el sistema radical. Al comparar dichos estudios, fue posible demostrar que el recipiente es limitante para el desarrollo y que en diferentes ocasiones, el sistema radical no logra superar la barrera de algodón, lo cual genera obstrucción de las raíces secundarias para expandirse dentro de la bolsa de almácigo a pesar que la nutrición de las mismas fuera suficiente, con la consecuente reducción del peso fresco de la planta. Lo anterior implica que el tipo de pellet, no sólo es reducido a nivel de volumen, sino que también su recubierta es más fuerte que la capacidad radical para romperla. Una posible solución a dicho problema, puede radicar en eliminar la radícula proveniente del laboratorio durante la aclimatización, con el objetivo de estimular el desarrollo de una nueva raíz con mayor vigorosidad y fuerza similar a lo acontecido durante el desarrollo de estacas (Barry-Etienne et ál. 2002a).

Según lo anterior, el área de la biotecnología, puede dar soluciones para la adecuación de la tecnología a las necesidades de producción, tiempo, volumen y calidad (De los Santos y Hernández 2006, Costa et ál. 2008).

\section{CONCLUSIONES}

Las malformaciones de las plántulas desarrolladas ex vitro, tienen su origen en primera instancia, durante el proceso de germinación y desarrollo del sistema de inmersión temporal tipo RITA $®$, las cuales dificultan el desarrollo posterior a nivel del almácigo, evidentes en más de una malformación por planta, y con variable grado de intensidad superiores al $77 \%$.

Se recomienda por ende mejorar la técnica de inmersión temporal para garantizar mejor calidad de los embriones generados a través del proceso de embriogénesis así como mejora en la clasificación del material previo a la aclimatización ex vitro.

La utilización de Jiffy® para el proceso de aclimatización, muestra ser una muy buena alternativa con respecto a la mezcla de sustrato, sin embargo, mantener la cubierta durante el almácigo, disminuye el desarrollo de la planta debido al impedimento de salida y deformación del sistema radical que además reduce hasta un 50\% el peso total de la planta.

El desarrollo de las plantas con mejor sistema radical (recto), revela un peso superior de 40 gramos y $10 \mathrm{~cm}$ más de altura apical, por lo que es la planta más deseable a seleccionar para desarrollo en almácigo. 
Se debe continuar la optimización de la técnica de embriogénesis somática para la multiplicación de materiales promisorios como los Híbridos F1, así como los procesos de aclimatización que lleven a rendimientos más altos que disminuyan los costos y mejoren la calidad del almácigo.

\section{AGRADECIMIENTOS}

Los autores agradecen la colaboración brindada por el personal de Agribiotecnología de Costa Rica S.A., especialmente al Dr. Oscar Arias Moreira e Ing. Oscar Arias Rosabal por su atención e interés en el estudio.

\section{LITERATURA CITADA}

AZOFEIFA J., ROJAS A., HINE A. 2009. Optimización del proceso de enraizamiento y aclimatización de vitroplantas de Swietenia macrophylla King (Orden: Meliacea). Tecnología en Marcha 22(3):34-41.

BARRY-ETIENNE D., BERTRAND B., VASQUES N., ETIENNE H. 2002(a). Comparison os fomatic embryogenesis-derived Coffee (Coffea arábica L.) plantlets regerated in vitro or ex vitro: Morphological, Mineral and Water Characteristics. Annals of Botanny 90:77-85.

BARRY-ETIENNE D., BERTRAND B., SCHLÖNVOIGHT A., ETIENNE H. 2002(b). The morphologycal variability within a population of coffee somatic embryos produced ina biorreactor affects the regeneration and the developmente of plants in the nursery. Plant Cell, Tissue and Organ Culture 68:153-162.

BOXTEL J., BERTHOULY M. 1995. High frequency somatic embryogenesis from coffee leaves. Plant Cell, Tissue and Organ Culture 44:7-17.

BERTHOULY M., MICHAUX-FERRIERE N.M. 1996. High frequency somatic embryogenesis from Coffea canephora. Plant Cell, Tissue and Organ Culture 44:169-176.
COSTA J., FERREIRA E., PASQUAL M., VILLA F., BOTELHO C., PEREIRA S. 2008. Development of Coffea Arabica L., seedlings obtained form direct somatic embryogenesis. Coffee Science 3(1):30-37.

DE LOS SANTOS C., HERNÁNDEZ T. 2006. Coffee Biotechnology. Braz. J. Plant Physiol. 18(1):217-227.

ETIENNE H., ANTHONY F., DUSSERT S., FERNANDEZ D., LASHERMES P., BERTRAND B. 2002. Biotechnological applications for the improvement of Coffee (Coffea arabica L.). In Vitro Cell. Dev. Biol. Plant. 38:129-138.

ETIENNE H., BARRY-ETIENNE D., VASQUEZ N., BERTHOULY M. 1999. Aportes de la biotecnologia al mejoramiento genético del café: el ejemplo de la multiplicacion por embriogénesis somatica de hibridos F1 en America Central, pp. 457-493. In: B. Bertrand y B. Rapidel (eds.). Desafios de la caficultura en Centroamerica. San Jose: IICA.

ETIENNE H., SOLANO W., PEREIRA A., BARRY D., BERTRAND B., ANTHONY F., CÔTE F., BERTHOULY M. 1998. La propagación masal de los híbridos F1 de cafés arábigos. Boletin PROMECAFE (80):12-15.

GATICA A., ARRIETA G., ESPINOZA A. 2007. Comparison of three in vitro protocols for direct embryogenesis and plant regeneration of Coffea arabica L. Cvs. Caturra and Catuaí. Agronomía Costarricense 31(1):85-94.

LEBUDE A., GOLDFAED B., BLAZICH F., WRIGHT J., CAZELL B., WIZE F., FRAMPTON J. 2006. Container type and volumen influences adventitious rooting and subsequent field growth of stem cuttings of Loblolly pine. SJAF. 30(30):123-131.

ROJAS F., ARIAS D., MOYA R., MEZA A., MURILLO O., ARGUEDAS M. 2004. Manual para productores de melina Gmelina arbórea en Costa Rica. Cartago. $314 \mathrm{p}$.

STARITSKY G. 1970. Embryoid formation in callus tissues of coffee. Acta Bot. Need. 19:509-514.

SÖNDAHL M., SHARP W., 1977. High frecuency induction of somatic embryos in cultured leaf explants of Coffea arabica L. Zeitschriff fûr Pflanzenphysiologie. 81:395-408

YASUDA T., FUJII Y., YAMAGUCHI T. 1985. Embryogenic callus induction from Coffea arabica leaf explants by benzyladenine. Plant Cell Physiol. 26:595-597. 